Saudi Journal of Biomedical Research

Abbreviated Key Title: Saudi J Biomed Res ISSN 2518-3214 (Print) |ISSN 2518-3222 (Online)

\title{
Assessment of Seminal Plasma Trace Elements among Infertile Sudanese Males in Khartoum State, 2019
}

Mutaz Ibrahim Hassan ${ }^{1 *}$, Abdelrhman Mohamed Sid Ahmed ${ }^{2}$, Mosab Nouraldein Mohammed Hamad ${ }^{3}$, Gamal Mahmoud Elimairy $^{4}$

${ }^{1}$ Faculty of Medical Laboratory Science, Shendi University, Shendi, Sudan

${ }^{2}$ Clinical Chemistry Department, Faculty of Medicine, Kassala University, Kassala, Sudan

${ }^{3}$ Medical Laboratory Science Department, Faculty of Health Science, Elsheikh Abdallah Elbadri University, Sudan

${ }^{4}$ Faculty of Medicine, Elrazi University, Azhari Road, Khartoum North, Sudan

DOI: $10.36348 /$ sjbr.2020.v05i01.003

| Received: 01.01.2020 | Accepted: 16.01.2020 | Published: 30.01.2020

*Corresponding author: Mutaz Ibrahim Hassan

\section{Abstract}

Background: Male infertility is a multifaceted state and overlaps a lot of factors and affects infertility in about 8-5\% of the people in the world and the man is responsible for $40 \%$ of these cases. Dietary insufficiency of trace element, zinc and copper may play a role in male infertility as trace element plays an important role not only in normal testicular improvement, but also in spermatogenesis and sperm motility. Objective: The current study was intended to analyze the level of seminal plasma trace elements mainly zinc and copper amongst dissimilar groups of infertile men. Method: The concentrations of zinc and copper were measured in 160 semen samples from normozoospermic, oligoathenospermic, and azoospermic men using the atomic absorption spectroscopy, data was analyzed using the statistical software package SPSS version 17. Result: Outcomes showed that the mean values of seminal plasma zinc concentrations were significantly decreased in the two groups of infertile male subjects, azoospermic (P.value $=0.000$ ), and oligozoospermic (P.value $=0.013$ ) compared with fertile males, while there was significant decrease in seminal plasma copper concentration of azoospermic patients compared to control (P.value $=0.000$ ), and significant decrease in oligozoospermic patients compared to control (P.value $=0.000)$.

Keywords: Seminal Plasma, Trace Elements Infertile Male.

Copyright @ 2020: This is an open-access article distributed under the terms of the Creative Commons Attribution license which permits unrestricted use, distribution, and reproduction in any medium for non-commercial use (NonCommercial, or CC-BY-NC) provided the original author and source are credited.

\section{INTRODUCTION}

Infertility is complicated and has manifold reasons and outcomes depending on the sex, sexual history, life style and cultural environment [1]. Infertility have an effect on about $8 \%$ to $12 \%$ of the world's population and in about half of cases, men are either the single reason or add to couple's infertility [2]. Seminal plasma is very vital for sperm metabolism, function, survival, and transport in the female genital tract. Cations such as $\mathrm{Na}, \mathrm{K}, \mathrm{Ca}$, and $\mathrm{Mg}$ set up osmotic balance, as necessary trace elements are components of several essential enzymes in the seminal plasma [3]. The probable effect of the trace elements particularly $\mathrm{Cu}$ and $\mathrm{Zn}$ on male infertility is a topic of great interest [1], rising proof of a direct association of zinc was found with seminal parameters [4]. Zinc is the second major element, after iron, in seminal plasma. It maintains the cell membrane and nuclear chromatin of spermatozoa [5]. It may also have an antibacterial role [6], defends testis from the degenerative alterations [7].
It regulates mechanism of capacitation and acrosome reaction [8]. Zinc has a significant function in normal testicular growth, spermatogenesis and sperm motility [9]. It is a cofactor for a number of metalloenzymes in human semen, concerned in DNA transcription and protein production. Shortage of zinc in the reproductive system leads to hypogonadism and gonadal hypo function $[6,10,11]$ reported that zinc in seminal plasma is implicated in nuclear chromatin decondensation and acrosin activity. Zinc insufficiency in the nucleus may destabilize the quaternary structure of chromatin; a characteristic essential for the fertilizing capability of the spermatozoa $[12,13]$ conducted an experiment in adult males and reported that production of testosterone b $[14,8]$. Preceding study discussed the role of zinc in exchange of testosterone into its biologically active form $5 \alpha$-dihydrotestosterone (DHT) and mentioned that reduction of dietetic zinc May reduce semen volume and serum testosterone levels [15]. Zinc content in seminal plasma is mostly secreted by the prostate gland and may reflect prostatic function. Copper is an 
imperative element for many metalloenzymes and metalloproteins that are concerned in energy metabolism. It works in diverse ways in order to preserve normal environment for spermatozoa for normal fertilization to occur [16]. Though, a higher level is toxic to a variety of cells, including human spermatozoa [16]. In vitro studies, established that utilize of $\mathrm{Cu}$ in intrauterine devices stop conception [16]. The recent study was intended to assess seminal plasma levels of zinc and copper and to correlate their concentrations with a variety of semen parameters between fertile and infertile Sudanese male.

\section{Rationale}

The determination of spermatozoa concentration, morphology and motility remains the primary clinical means for the evaluation of male infertility. Nutritional deficiency of trace element, zinc and copper may engage in recreation a role in male infertility.

This study aimed to enrich data about the level of these vital trace elements between infertile Sudanese men.

\section{OBJECTIVES}

\section{General objective}

To assess the seminal plasma trace elements among infertile Sudanese males in Khartoum state.

\section{Specific Objectives}

- To estimate seminal plasma zinc \& copper among infertile males.

- To compare between Azoospermia and Oligoasthenospermia in the level of seminal plasma trace elements.

\section{MATERIALS AND METHODS \\ Study design \\ Case control hospital based study.}

\section{Study area}

Reproductive care center in Almuk Nemer Street in Khartoum state.

\section{Study Duration}

The study was carried out during the period from December 2016 to September 2019.

\section{Study Population}

Infertile Sudanese male referred to the study setting, by various fertility centers and hospitals in Khartoum state during study period.

\section{Inclusion Criteria}

Males with oligoasthenospermia and azoospermia as test group and normal males (age group $24-78$ years) belong to the same socioeconomic status were selected as control group.

\section{Exclusion Criteria}

Infertile men under hormonal treatment and diabetic patients.

\section{Sample Size and Study population}

One hundred and sixty blood samples were collected in this study.

Case group: 80infertile male patients (oligoasthenospermia and azoospermia).

Control group: 80 apparently healthy individuals.

\section{Blood Sample Collection and Analysis}

Before collection, a local antiseptic $(70 \%$ alcohol) was used to clean the skin, venous blood (about $4 \mathrm{ml}$ ) was be taken from each participant in lithium heparin container, then the centrifugation will be done at $3000 \mathrm{rpm}$ for 3-5 minute to obtain plasma, used for measurement of zinc and copper.

\section{Collection of Semen Samples and analysis}

Semen was collected by masturbation into a sterile plastic specimen container at the hospital. Subjects were instructed to abstain from ejaculation for at least 72 hours prior to producing the semen sample. The sample was liquefied for at least 20 minutes, but no longer than 1 hour prior to performing a routine semen analysis, which included measurements of volume, $\mathrm{pH}$, sperm concentration, sperm motility and morphology and direct microscopic examination.

Estimation of sperm counting will be done using the Neubauer chamber. Sperm analysis was carried out according to the World Health Organization guidelines, based on the sperm concentration the infertile subjects were classified as follows:

- Normozoospermia (> 20 million sperm /ml and normal semen profile)

- Oligoasthenospermia (<20 million sperm/ml and motility grade $\mathrm{C}$ or $\mathrm{D})$

- Azoospermia (no spermatozoa)

In proven fertile controls, the sperm count ranged from $20-120$ million sperm $/ \mathrm{ml}$

\section{Seminal Plasma Collection and Analysis Sample Preparation \\ Seminal plasma specimens were diluted 1:10 with $0.5 \% \mathrm{v} / \mathrm{v} \mathrm{HNO}_{3}$ to determine the concentrations of zinc and copper.}




\section{Instrument}

Atomic absorption spectrophotometer (Buck Scientific, model 210 VGP).

\section{Principle of Atomic Absorption Spectrophotometer}

Atomic absorption spectrophotometer utilizes the phenomenon that atoms absorb, radiation of particular wavelength. When the light from a hollow cathode lamp shines into the flame, ground state atoms of the element wanted to be measured absorb some of the light resulting in a decrease of the light (atomic absorption).

\section{Data Collection}

Direct questionnaire was done to obtain clinical data for each participant and sample.

\section{Data Analysis}

Data was analyzed using Statistical Package for Social Science Software (SPSS).

\section{Ethical Considerations}

This study was approved by the research committee - College of Medical Laboratory Sciences Shendi University. Informed consent was obtained from each participant before taking the samples.

\section{RESULTS}

This is a case control hospital based study conducted in Khartoum state in the Reproductive Care Center during the period from December 2016 to September 2019. This study included 160 samples, 80 from these samples were collected from infertile males as case group (40 of them collected from Azoospermia25\% and the rest from Oligoathenospermia25\%) and the rest of the samples collected from normal male (Normozoospermia 50\%) as control group. The results of the study were presented in texts and tables.

Table-1: Independent sample T.test showed mean and std. deviation of seminal plasma Copper among case group (Azoospermia and Oligoasthenospermia) and Control group

\begin{tabular}{|l|l|l|l|l|}
\hline \multirow{2}{*}{} & \multicolumn{2}{|l|}{ Azoospermia } & \multicolumn{2}{l|}{ Oligoasthenospermia } \\
\cline { 2 - 5 } & Case & Control & Case & Control \\
\hline No & 40 & 80 & 40 & 80 \\
\hline Mean (mg/dl) & 0.05 & 0.13 & 0.057 & 0.123 \\
\hline Std. Dev & 0.038 & 0.037 & 0.035 & 0.037 \\
\hline P. Value & 0.000 & 0.000 \\
\hline
\end{tabular}

Table-2: Independent sample T. test showed mean and std. deviation of seminal plasma Zinc among case (Azoospermia and Oligoasthenospermia) group and Control group

\begin{tabular}{|l|l|l|l|l|}
\hline \multirow{2}{*}{} & \multicolumn{2}{|l|}{ Azoospermia } & \multicolumn{2}{l|}{ Oligoasthenospermia } \\
\cline { 2 - 5 } & Case & Control & Case & Control \\
\hline No & 40 & 80 & 40 & 80 \\
\hline Mean (mg/dl) & 16.0 & 22.1 & 20.7 & 22.1 \\
\hline Std. Dev & 6.55 & 4.44 & 5.76 & 4.44 \\
\hline P. Value & \multicolumn{2}{|l|}{0.000} & 0.13 & \\
\hline
\end{tabular}

P. value $\leq 0.05$ is considered significant.

Table-3: Paired sample T. test showed Mean of seminal Trace elements among (Oligoasthenospermia) and Azoospermia

\begin{tabular}{|l|l|l|l|l|}
\hline Paired Group & Mean (mg/dl) & N & Std. Deviation & \multirow{2}{*}{ P. Value } \\
\hline Copper level AZO & 0.05 & 40 & 0.038 & \multirow{2}{*}{0.474} \\
\hline Copper level OAS & 0.056 & 40 & 0.035 & \\
\hline Zinc level AZO & 16.0 & 40 & 6.55 & \multirow{2}{*}{0.006} \\
\hline Zinc level OAS & 20.6 & 40 & 5.76 & \\
\hline
\end{tabular}

\section{DISCUSSION}

Statistical analysis of the gathered data shows significant decrease in mean of seminal plasma Copper among case (Azoospermia) group compared to Control group with $\mathrm{P}$. Value (0.000). The results revealed a marked decrease in seminal plasma copper in case (oligoasthenospermia) group, mean $(0.057 \mathrm{mg} / \mathrm{l})$ while it is $(0.123 \mathrm{mg} / \mathrm{l})$ in control group. Agree with $[17,18]$
The laboratory analysis for seminal plasma samples demonstrate very low level of zinc in patients with azoospermia compared to control group with mean of $(16.0 \mathrm{mg} / \mathrm{l})$ and (22.1) respectively. also the results show insignificant decrease in seminal plasma zinc level among patients with oligoasthenospermia compared to control group, with mean of $(20.7 \mathrm{mg} / \mathrm{l})$ and $(22.1 \mathrm{mg} / \mathrm{l})$ respectively. This result agrees with Yosra M et al 2015and Mohammad Shoaib Khan 2011. 
The trace elements $\mathrm{Zn}$ and magnesium $(\mathrm{Mg})$ found in seminal plasma originate primarily from the prostate gland and may reflect prostatic secretary function. Studies have suggested that $\mathrm{Mg}$ may play a role in spermatogenesis, particularly in sperm motility [19]. The same is true for $\mathrm{Zn}$, although the results of several studies are still contradictory [20]. Zn, B complex vitamins (B6, B12 and folic acid), vitamin C, and antioxidants are critical nutrients in the male reproductive system for proper hormone metabolism, sperm formation, and motility [21]. Moreover, a positive correlation has been observed between the sperm count and seminal plasma Zn concentration in oligozoospermic and azoospermic patients [22].

\section{CONCLUSION}

According to our result, we conclude that there was significant decrease in seminal zinc and copper in patients with azoospermia and oligoasthenospermia as compared with control group.

\section{RECOMMENDATIONS}

According to our outcomes we recommend:

- Molecular based study to confirm effect of zinc deficiency on the spermatozoa integrity.

- Experimental supplementation of zinc \& copper for patients with Azoospermia and Oligoasthenospermia.

- Health education plan should be achieved to aware population for the significance of micronutrient.

\section{REFERENCES}

1. Gurunath, S., Pandian, Z., Anderson, R. A., \& Bhattacharya, S. (2011). Defining infertility-a systematic review of prevalence studies. Human reproduction update, 17(5), 575-588.

2. Barnett, B. (2003). Men contribute to and suffer from infertility. Network, 23(2), 17-18.

3. Meizel, S. (1997). Amino acid neurotransmitter receptor/chloride channels of mammalian sperm and the acrosome reaction. Biology of reproduction, 56(3), 569-574.

4. Stanwell-Smith, R., Thompson, S. G., Haines, A. P., Ward, R. J., Cashmore, G., Stedronska, J., \& Hendry, W. F. (1983). A comparative study of zinc, copper, cadmium, and lead levels in fertile and infertile men. Fertility and sterility, 40(5), 670-677.

5. Kvist, U. (1980). Sperm nuclear chromatin decondensation ability. Acta physiologica Scandinavica. Supplementum, 486, 1-24.

6. Langley, J. G., Goldsmid, J. M., \& Davies, N. (1987). Venereal trichomoniasis: role of men. Sexually Transmitted Infections, 63(4), 264267.

7. Batra, N., Nehru, B., \& Bansal, M. P. (2004). Reproductive potential of male Portan rats exposed to various levels of lead with regard to zinc status. British journal of nutrition, 91(3), 387391.

8. Wong, W. Y., Flik, G., Groenen, P. M., Swinkels, D. W., Thomas, C. M., Copius-Peereboom, J. H., ... \& Steegers-Theunissen, R. P. (2001). The impact of calcium, magnesium, zinc, and copper in blood and seminal plasma on semen parameters in men. Reproductive toxicology, 15(2), 131-136.

9. Ebisch, I. M. W., Thomas, C. M. G., Peters, W. H. M., Braat, D. D. M., \& Steegers-Theunissen, R. P. M. (2007). The importance of folate, zinc and antioxidants in the pathogenesis and prevention of subfertility. Human reproduction update, 13(2), 163-174.

10. Sandstead, H. H., Prasad, A. S., Schulert, A. R., Farid, Z., Miale Jr, A. U., Bassilly, S., \& Darby, W. J. (1967). Human zinc deficiency, endocrine manifestations and response to treatment. The American journal of clinical nutrition, 20(5), 422442.

11. Steven, F. S., Griffin, M. M., \& Chantler, E. N. (1982). Inhibition of human and bovine sperm acrosin by divalent metal ions. Possible role of zinc as a regulator of acrosin activity. International journal of andrology, 5(4), 401-412.

12. Prasad, A. S. (1991). Discovery of human zinc deficiency and studies in an experimental human model. The American journal of clinical nutrition, 53(2), 403-412.

13. Netter, A., Nahoul, K., \& Hartoma, R. (1981). Effect of zinc administration on plasma testosterone, dihydrotestosterone, and sperm count. Archives of andrology, 7(1), 69-73.

14. Hunt, C. D., Johnson, P. E., Herbel, J., \& Mullen, L. K. (1992). Effects of dietary zinc depletion on seminal volume and zinc loss, serum testosterone concentrations, and sperm morphology in young men. The American journal of clinical nutrition, 56(1), 148-157.

15. Skandhan, K. P. (1992). Review on copper in male reproduction and contraception. Revue française de gynécologie et d'obstétrique, 87(12), 594-598.

16. Roblero, L., Guadarrama, A., Lopez, T., \& Zegers-Hochschild, F. (1996). Effect of copper ion on the motility, viability, acrosome reaction and fertilizing capacity of human spermatozoa in vitro. Reproduction, fertility and development, 8(5), 871-874.

17. Altaher, Y. M., \& Abdrabo, A. A. (2015). Levels of Zinc and Copper in seminal plasma of Sudanese infertile males. Journal of Advances in Medicine and Medical Research, 533-538.

18. Khan, M. S., Zaman, S., Sajjad, M., Shoaib, M., \& Gilani, G. (2011). Assessment of the level of trace element zinc in seminal plasma of males and evaluation of its role in male infertility. International Journal of Applied and Basic Medical Research, 1(2), 93-96. 
19. Abou-Shakra, F. R., Ward, N. I., \& Everard, D. M. (1989). The role of trace elements in male infertility. Fertility and sterility, 52(2), 307-310.

20. Lewis-Jones, D. I., Aird, I. A., Biljan, M. M., \& Kingsland, C. R. (1996). Andrology: Effects of sperm activity on zinc and fructose concentrations in seminal plasma. Human reproduction, 11(11), 2465-2467.
21. Czeizel, A. E. (1998). Periconceptional folic acid containing multivitamin supplementation. European Journal of Obstetrics \& Gynecology and Reproductive Biology, 78(2):151-161.

22. Ali, H., Ahmed, M., Baig, M., \& Ali, M. (2007). Relationship of zinc concentrations in blood and seminal plasma with various semen parameters in infertile subjects. Pakistan Journal of Medical Sciences, 23(1), 111. 